\title{
EFEITO DA COBERTURA DE Pinus taeda L. NA PROTEÇÃO CONTRA GEADAS E NO CRESCIMENTO DE PLANTAS JOVENS DE Eucalyptus dunnii MAIDEN
}

\author{
Mário Dobner Júnior ${ }^{1}$, Antônio Rioyei Higa ${ }^{2}$, Rudi Arno Seitz ${ }^{3}$ \\ ${ }^{1}$ Eng. Florestal, M.Sc., Florestal Gateados Ltda., Campo Belo do Sul, SC, Brasil - mario@ gateados.com.br \\ ${ }^{2}$ Eng. Florestal, Ph.D., Depto. de Ciências Florestais, UFPR, Curitiba, PR, Brasil - higa@ufpr.br \\ ${ }^{3}$ Eng. Agrônomo, Dr., Depto. de Ciências Florestais, UFPR - in memoriam
}

Recebido para publicação: 19/08/2008 - Aceito para publicação: 16/02/2009

\begin{abstract}
Resumo
Este estudo teve como objetivo avaliar os efeitos da cobertura de Pinus taeda na proteção contra geadas e no crescimento de plantas jovens de E. dunnii. O trabalho foi desenvolvido no município de Capão Alto, SC. Três diferentes intensidades de cobertura foram estabelecidas a partir de um povoamento de $P$. taeda com 23 anos de idade: bordadura (TB), com árvores apenas no perímetro do talhão; 20 (T20) e 50 (T50) árvores por hectare na cobertura. Por último, a testemunha (TCA), onde as plantas de E. dunnii cresceram a céu aberto. Apesar de todas as plantas de E. dunnii apresentarem danos causados por geadas, com temperaturas de até $-5{ }^{\circ} \mathrm{C}$, independentemente do tratamento ao qual estavam expostas, conclui-se que o aumento da intensidade de cobertura até 50 árvores de $P$. taeda por hectare diminui os danos causados por geadas. Quanto maior a intensidade de cobertura, até 50 árvores de $P$. taeda por hectare, menor é o crescimento em altura e diâmetro do colo do E. dunnii, antes e após as geadas. O sistema de plantio sob cobertura é uma forma de diminuir os danos em plantas de E. dunnii em regiões com invernos severos.

Palavras-chave: Plantio sob cobertura; proteção contra geadas; Eucalyptus dunnii.
\end{abstract}

\begin{abstract}
Effects of a Pinus taeda L. shelterwood on frost protection and growth of Eucalyptus dunnii Maiden young plants. This paper aimed to evaluate the effects of three Pinus taeda shelterwoods intensities on frost protection and growth of $E$. dunnii young plants. The study was developed in the district of Capão Alto, SC. Three different shelter intensities were established from a 23 years old $P$. taeda plantation: trees only in the perimeter of the stand (TB), 20 (T20) and 50 (T50) trees per hectare. The control, a clear-cut (TCA), was also located. Despite plants of E. dunnii were damaged by frosts with temperatures of until $-5^{\circ} \mathrm{C}$, independent of the treatment to which they were exposed, the increase of the shelter intensity, until 50 trees per hectare, decreased the damages caused by frosts. It was also verified that as more intensive the shelter, lower was the growth in height and diameter of the $E$. dunnii, before and after the frosts. This technique is recommended for the establishment of E. dunnii in areas with severe winters.
\end{abstract}

Keywords: Shelterwood; frost protection; Eucalyptus dunnii.

\section{INTRODUÇÃO}

O aumento na demanda da madeira de eucalipto no Sul do Brasil é evidente. Espécies como Eucalyptus grandis Hill ex Maiden e Eucalyptus dunnii já são utilizadas pelas indústrias de base florestal de Santa Catarina, além de serem consideradas de grande potencial para a produção de painéis e compensados estruturais (IWAKIRI et al., 2007). Nutto et al. (2006) também relatam uma crescente utilização da madeira de eucalipto na fabricação de móveis no Brasil.

Porém o cultivo de eucalipto é restringido no Sul do Brasil e em muitas partes do mundo em função da ocorrência de geadas, que é o principal fator limitante à eucaliptocultura nessas regiões (HIGA, 1989; FERREIRA, 1989). 
Um fato agravante para a região de estudo é a grande amplitude de variação térmica, mesmo em períodos mais frios, que não permite a aclimatação das plantas. Além disso, podem ocorrer geadas no início da primavera ou final do outono, quando a planta apresenta pouca ou nenhuma rustificação.

Em eucaliptos, as geadas causam a morte de brotações e trincas no tronco, onde posteriormente ocorre a entrada de micro-organismos, especialmente fungos e patógenos fracos. Em seguida, com a reação da árvore por calejamento, têm-se cancros típicos no tronco injuriado (FERREIRA, 1989).

O gênero Eucalyptus, assim como outras plantas, é relativamente pouco sensível às mudanças no fotoperíodo no que diz respeito ao desenvolvimento de resistência ao frio (KOZLOWSKI et al., 1991).

Além da resistência a geadas, tem-se a resiliência, que é a capacidade de um indivíduo voltar ao normal após ter sido danificado, ou ainda a capacidade de recuperação de uma planta após ter sido exposta a fatores adversos (HIGA et al., 2000). Dessa forma, trabalhos que avaliem danos causados por geadas devem incluir também a avaliação da recuperação das plantas.

Os efeitos da ocorrência de temperaturas iguais ou inferiores a $0{ }^{\circ} \mathrm{C}$, geadas, pode ser evitada com a presença de uma cobertura arbórea, da mesma forma que noites nubladas diminuem a perda de calor por radiação da superfície da Terra para a atmosfera.

O microclima dentro de uma área florestal é muito diferente daquele em área aberta. A amplitude de variação térmica próxima ao solo é muito maior em áreas abertas, com maior duração da incidência de luz solar e temperaturas noturnas mais baixas (LANGVALL; LÖFVENIUS, 2002).

Dependendo do tipo e intensidade da cobertura, bem como das espécies envolvidas, o microclima sob tais condições pode afetar positiva ou negativamente as plantas. Segundo Strand et al. (2006), o crescimento das plantas sob cobertura é afetado, entre outros fatores, pelas condições de luminosidade, umidade e disponibilidade de nutrientes no solo. O gênero Eucalyptus requer uma forte redução das árvores que compõem o estrato superior para que o estabelecimento de novas plantas seja possível, bem como para o seu crescimento normal (WALTERS; BELL, 2005).

Alguns autores (SMITH, 1986; MATTHEWS, 1989) citam a sobreposição de rotações como uma vantagem no que diz respeito à utilização do espaço produtivo. As árvores da rotação anterior somente são colhidas quando as novas árvores ocupam boa parte do espaço produtivo e estão aptas a utilizá-lo de forma eficiente, não expondo totalmente o solo, como se observa no corte raso.

Com o passar do tempo, a cobertura deve ser eliminada, pois a competição entre as plantas dos dois estratos pode afetar negativamente o crescimento das plantas do estrato inferior. Assim, a intensidade ideal de cobertura deve combinar a proteção contra geadas e o menor efeito negativo sobre o crescimento das plantas jovens.

Apesar dos possíveis efeitos negativos no crescimento das plantas e da possibilidade de danos a elas nas operações de remoção da cobertura, o plantio de E. dunnii sob cobertura de Pinus taeda L. pode ser mais uma ferramenta na formação de povoamentos de $E$. dunnii em regiões onde a geada é fator limitante.

Este trabalho teve como objetivo geral avaliar os efeitos da cobertura de $P$. taeda em plantas jovens de E. dunnii, considerando a proteção contra geadas e o crescimento. Para isso, os objetivos específicos foram:

a) Avaliar os efeitos de diferentes intensidades de cobertura de $P$. taeda sobre plantas de E. dunnii com relação aos danos causados por geadas e à resiliência das plantas afetadas por elas.

b) Avaliar o crescimento em altura e diâmetro das plantas de E. dunnii sob as diferentes intensidades de cobertura de $P$. taeda, antes e após as geadas.

c) Determinar a intensidade de cobertura adequada para o estabelecimento de plantios de E. dunnii nas condições estudadas.

d) Quantificar os danos causados pela remoção da cobertura de P. taeda às plantas de E. dunnii com um ano de idade.

\section{MATERIAL E MÉTODOS}

O experimento foi instalado em uma área pertencente à empresa Florestal Gateados Ltda., no município de Capão Alto, Santa Catarina, distante $50 \mathrm{~km}$ da cidade de Lages, em linha reta, sentido sudoeste $\left(28^{\circ} 03^{\prime} 26^{\prime}\right.$ 'S e $50^{\circ} 46^{\prime} 13^{\prime}$ 'W). A área experimental está compreendida dentro da Região Bioclimática 1 do estado de Santa Catarina, classificada assim pela EMBRAPA (1988). 
De acordo com a classificação de Köppen, o clima da área de estudo é predominantemente do tipo $\mathrm{Cfb}$, mesotérmico, subtropical úmido, com verões frescos, sem estações secas definidas e com ocorrência de geadas severas. Esse tipo climático é comum no Planalto Meridional Brasileiro. A temperatura média anual é de 12 a $19{ }^{\circ} \mathrm{C}$, a média mínima de 5 a $8{ }^{\circ} \mathrm{C}$, a média máxima de 22 a $31{ }^{\circ} \mathrm{C}$ e a mínima absoluta $-12{ }^{\circ} \mathrm{C}$. A precipitação anual fica em torno de 1.300 a $2.400 \mathrm{~mm}$. A frequência com que as geadas ocorrem varia de 2 a 29 por ano (EMBRAPA, 1988).

Os solos da área de estudo são originados de riodacito, rocha efusiva da formação Serra Geral. O solo de maior representatividade do local é o Nitossolo Háplico, com associações de Cambissolo e Neossolo Litólico nas áreas mais declivosas. São solos minerais, não hidromórficos, argilosos, bem drenados, de coloração tipicamente brunada. Os horizontes superficiais apresentam-se bastante espessos e endurecidos, com elevados teores de matéria orgânica (GUEDES, 2005).

A área experimental foi utilizada como pastagem até o ano de 1982, quando foi plantada em parte com P. taeda. Na outra parte foi mantido o campo com roçadas anuais e sem o uso de fogo. Esse uso diferenciado do solo acarretou diferenças na sua densidade na camada 10 a $20 \mathrm{~cm}$ de profundidade. Em amostragem realizada através do método de anel volumétrico, encontraram-se valores médios de 1,18 $\mathrm{g} / \mathrm{cm}^{3}$ e $1,04 \mathrm{~g} / \mathrm{cm}^{3}$ para a área de campo e a área reflorestada, respectivamente. Esses valores são estatisticamente diferentes, segundo o teste de Fischer-Behrens, com 95\% de probabilidade.

$\mathrm{O}$ que diferiu de forma mais pronunciada entre as duas condições foram a quantidade de magnésio (média para a área com pinus e alta para a área com campo) e a quantidade de potássio (muito baixa para a área com pinus e alta para a área de campo).

Com relação aos teores de $\mathrm{Al}$ trocável, observou-se que a concentração em centimol de carga por centímetro cúbico $\left(\mathrm{cmolc} / \mathrm{dm}^{3}\right)$ foi bastante superior na área com $P$. taeda $\left(4,5 \mathrm{cmolc} / \mathrm{dm}^{3}\right)$, em comparação com a área de campo $\left(1,9 \mathrm{cmolc} / \mathrm{dm}^{3}\right)$.

No povoamento de $P$. taeda com 23 anos de idade, realizou-se um inventário florestal com cinco parcelas circulares de $400 \mathrm{~m}^{2}$, das quais todos os DAPs, a altura das quatro árvores mais grossas e algumas outras alturas foram medidas. Para a classificação da área experimental em termos de índice de sítio, tomou-se como referência um intervalo de confiança de $95 \%$ de probabilidade.

Realizou-se um desbaste seletivo no povoamento de $P$. taeda, com o intuito de formar duas diferentes intensidades de cobertura, 20 (T20) e 50 (T50) árvores remanescentes por hectare. Houve também um terceiro tratamento, denominado bordadura (TB), onde foi mantida apenas uma "cortina" de árvores no perímetro do talhão, com distância máxima entre os extremos de 66 metros. Por último, a testemunha (TCA), onde as mudas de E. dunnii foram plantadas a céu aberto.

Com as diferentes coberturas já instaladas, foram medidos DAP, altura e diâmetro de copa das árvores da cobertura, este último com o auxílio de balizas topográficas. Determinaram-se assim as distâncias entre os extremos da copa e o centro da árvore, ou seja, quatro raios de projeção da copa, nas direções norte, sul, leste e oeste. Como os raios diferiam muito entre si numa mesma árvore, optou-se por não utilizar uma média simples dos raios para o cálculo da área da copa, e sim tomá-los dois a dois, calculando a quarta parte da área do círculo de projeção da copa (Fórmula 1):

$$
\text { Área da copa }=\left\{\begin{array}{l}
\left(\frac{R_{1} \times R_{2} \times \pi}{4}\right)+\left(\frac{R_{2} \times R_{3} \times \pi}{4}\right)+ \\
\left(\frac{R_{3} \times R_{4} \times \pi}{4}\right)+\left(\frac{R_{4} \times R_{1} \times \pi}{4}\right)
\end{array}\right\}
$$

Em que: $\mathrm{R}_{1}$ : raio no sentido norte;

$\mathrm{R}_{2}$ : raio no sentido leste;

$\mathrm{R}_{3}$ : raio no sentido sul;

$\mathrm{R}_{4}$ : raio no sentido oeste.

A caracterização das intensidades de cobertura com o número de árvores, a área basal ( $\left.\mathrm{m}^{2} / \mathrm{ha}\right)$ e a área das copas é mostrada na tabela 1 .

A média dos tratamentos representa, em termos gerais, as condições avaliadas neste trabalho. No entanto, para algumas variáveis, verifica-se grande variação entre as parcelas, como é o caso da área basal e área de copa no tratamento T20. 
Tabela 1. Intensidades de cobertura: número de árvores ( $\left.\mathrm{n}^{\circ} / \mathrm{hectare}\right)$, área basal $\left(\mathrm{m}^{2} / \mathrm{ha}\right)$ e área de copa $\left(\mathrm{m}^{2} / \mathrm{ha}\right.$ ) para os tratamentos com 20 (T20) e 50 (T50) árvores por hectare.

Table 1. Shelter intensities represented by number of trees $\left(\mathrm{n}^{\circ} / \mathrm{hectare}\right)$, basal area $\left(\mathrm{m}^{2} / \mathrm{ha}\right)$ and tree crown area for the treatments with 20 (T20) and 50 (T50) trees per hectare.

\begin{tabular}{|c|c|c|c|}
\hline Tratamentos & $\begin{array}{c}\text { Árvores } \\
\left(\mathbf{n}^{\circ} / \text { hectare }\right)\end{array}$ & $\begin{array}{c}\text { Área basal } \\
\left(\mathbf{m}^{2} / \mathbf{h a}\right)\end{array}$ & 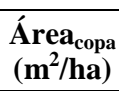 \\
\hline \multirow[t]{2}{*}{$\mathrm{T} 20$} & 20,8 & 2,7 & 517,7 \\
\hline & 24,1 & 6,1 & 737,2 \\
\hline Média ${ }_{\text {T20 }}$ & 22,4 & 4,4 & 624,4 \\
\hline \multirow[t]{2}{*}{$\mathrm{T} 50$} & 53,9 & 7,4 & $2.384,9$ \\
\hline & 58,6 & 7,6 & $1.923,3$ \\
\hline Média ${ }_{\text {T50 }}$ & 56,3 & 7,5 & $2.154,1$ \\
\hline
\end{tabular}

Os tratamentos TB e TCA não são apresentados na tabela 1, por não possuírem cobertura.

Após o corte de cobertura, realizou-se o preparo do solo, removendo-se os resíduos da colheita para fora da área avaliada.

Toda a área foi subsolada a aproximadamente $35 \mathrm{~cm}$ de profundidade. Utilizou-se implemento desenvolvido especialmente para esse uso, no qual havia disco frontal, com a finalidade de cortar as raízes presentes no solo, subsolador e enxada rotativa, responsável pelo destorroamento do solo.

O plantio das mudas de E. dunnii ocorreu em outubro de 2005, com adubação de $50 \mathrm{~g} / \mathrm{planta}$ de superfosfato triplo (NPK 00-42-00). Passados 90 dias do plantio, realizou-se adubação de cobertura, com mais $35 \mathrm{~g} /$ planta do mesmo adubo.

A figura 1 mostra as quatro diferentes intensidades de cobertura estudadas neste trabalho.

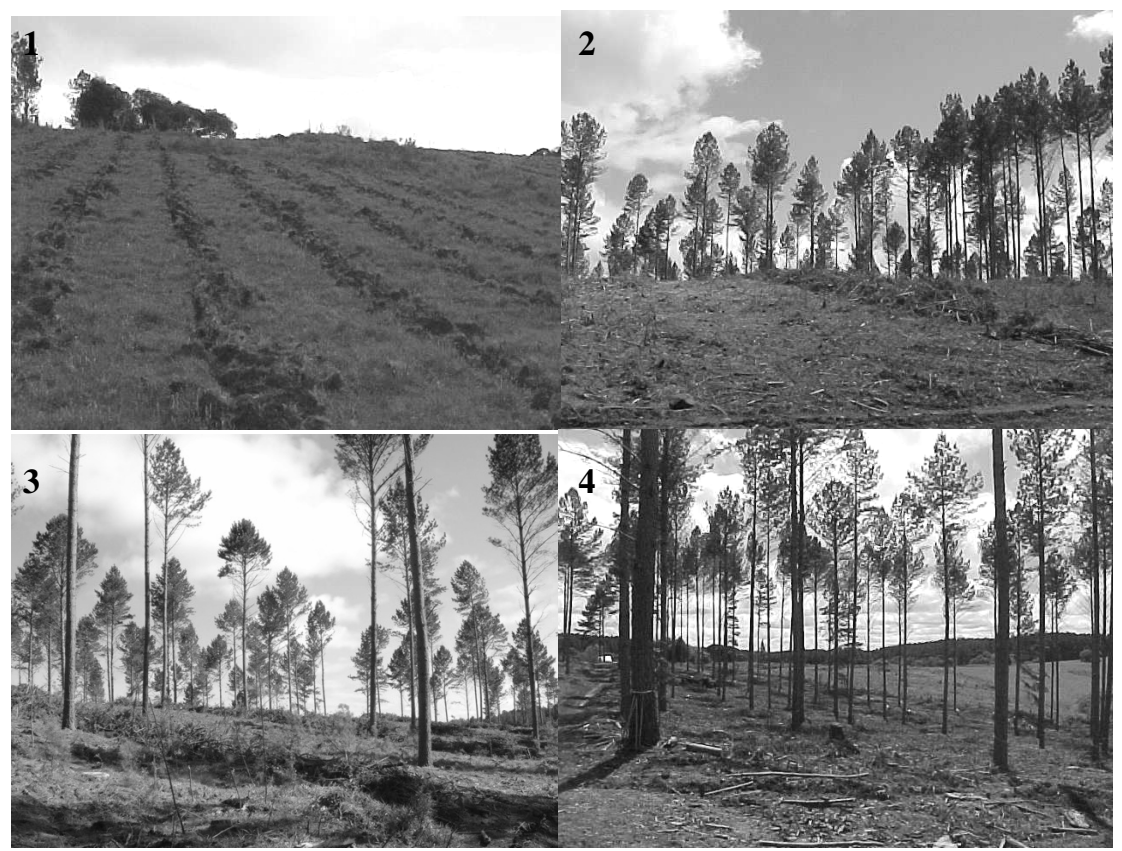

Figura 1. Céu aberto: TCA (1); bordadura: TB (2); 20 árvores por hectare: T20 (3); 50 árvores por hectare: T50 (4).

Figure 1. Clear cut: TCA (1); Trees in the perimeter: TB (2); 20 trees per hectare: T20 (3); 50 trees per hectare: T50 (4).

O experimento teve a duração de 17 meses, com início em novembro de 2005 e término em abril de 2007. Nesse período foram realizadas duas roçadas manuais.

A área ocupada por tratamento foi de 1,43, 2,64, 0,83 e 1,04 hectares, para 20 arv/ha (T20), 50 arv/ha (T50), bordadura (TB) e céu aberto (TCA), respectivamente, totalizando 5,73 ha. de área experimental. O perímetro do tratamento bordadura (TB) foi de $348 \mathrm{~m}$, e a distância entre as bordas de $66 \mathrm{~m}$. 
Com o uso de um luxímetro, caracterizou-se ainda a cobertura arbórea remanescente com relação à quantidade de luz que alcançava o solo nas diferentes intensidades de cobertura, em dois transectos perpendiculares dentro das parcelas. A intensidade luminosa média que chegou ao solo para os tratamentos TCA (1), T20 (2) e T50 (3) foi de 141.000, 115.000 e 99.000 LUX, respectivamente.

Deve-se ressaltar que, embora existam alguns locais com grande diferença na intensidade luminosa que alcançava o solo nas diferentes intensidades de cobertura, essa sombra foi pontual e móvel durante o dia, não permanecendo sobre uma única planta.

Os danos causados pelas geadas foram avaliados na forma de notas, como recomendado por Lisbão Jr. (1986).

No presente estudo, realizou-se uma listagem dos danos encontrados no TCA, antes da definição das classes. Essa listagem ajudou na identificação das diferentes classes de danos - classe 1 (sem dano) até 6 (morte de toda a parte aérea), mostradas na tabela 2.

Tabela 2. Classes utilizadas para a avaliação dos danos decorrentes de geadas.

Table 2. Classes for frost damages evaluation.

\begin{tabular}{ll}
\hline Classe de dano & Observações \\
\hline 1 & Sem dano \\
2 & Mudança de coloração das folhas \\
3 & Definhamento da gema apical \\
4 & Morte da gema apical \\
5 & Morte da gema apical e rachaduras no caule \\
6 & Morte de toda a parte aérea \\
\hline
\end{tabular}

A resiliência foi avaliada utilizando-se os dados de crescimento em altura, após a ocorrência das geadas. Dessa forma, tomou-se como variável indicadora o incremento médio em altura das plantas pertencentes a uma mesma classe de dano. As classes de dano " 2 " e " 3 " foram agrupadas por apresentarem valores próximos, ambos muito superiores às demais classes, além de serem, do ponto de vista prático, muito semelhantes no que diz respeito às consequências para a planta. Para a classe de dano "6", foram utilizadas as plantas que, embora tivessem sido classificadas como tal, não apresentaram morte de toda a parte aérea.

As medições foram realizadas em duas parcelas amostrais por tratamento, cada uma com aproximadamente 80 plantas e $400 \mathrm{~m}^{2}$, tomadas ao acaso dentro dos diferentes tratamentos, de forma a representar fielmente a população na qual estava inserida.

A comparação das médias foi realizada através do teste ou Problema de Fischer-Behrens (SACHS, 1973). Nesse caso, para dois valores médios cujas variâncias populacionais são heterogêneas $\left(\sigma^{2} \neq \sigma_{2}^{2}\right)$, testa-se a hipótese alternativa, ou seja, se as médias são diferentes $\left(\mu_{1} \neq \mu_{2}\right)$, com a seguinte fórmula (Fórmula 2):

$$
t^{\prime}=\frac{\bar{x}_{1}-\bar{x}_{2}}{\sqrt{\frac{S_{1}{ }^{2}}{n 1}+\frac{S_{2}{ }^{2}}{n_{2}}}}
$$

Em que: $t^{\prime}=$ valor $\mathrm{t}$ calculado;

$x_{I}=$ média da amostra $1 ;$

$x_{2}=$ média da amostra 2 ;

$S_{I}^{2}=$ variância da amostra 1 ;

$S_{2}^{2}=$ variância da amostra 2 ;

$n_{1}=$ número de observações da amostra $1 ;$

$n_{2}=$ número de observações da amostra 2 .

Os valores em porcentagem foram transformados em arc.sen $\sqrt{\%}$ para efeito de análise estatística.

Segundo Borges; Ferreira (1999), o valor $t$ ' não segue a distribuição de $t$ de Student. Uma aproximação, proposta por Satterthwaite ${ }^{1}$ (1946), citado por Borges; Ferreira (1999), refere-se ao cálculo

${ }^{1}$ SATTERTHWAITE, F. E. An approximate distribution of estimates of variance components. Biometric Bulletin, London, v. 2, p. 110-114, 1946. 
do número de graus de liberdade para $t^{\prime}$, de tal forma que a distribuição de $t$ possa ser usada. Os graus de liberdade são calculados pela Fórmula 3.

$$
v=\frac{\left(\frac{S_{1}^{2}}{n 1}+\frac{S_{2}{ }^{2}}{n_{2}}\right)^{2}}{\frac{\left(\frac{S_{1}^{2}}{n 1}\right)^{2}}{n 1-1}+\frac{\left(\frac{S_{2}^{2}}{n_{2}}\right)^{2}}{n_{2}-1}}
$$

Em que: $v=$ graus de liberdade;

$S_{I}^{2}=$ variância da amostra 1 ;

$S_{2}^{2}=$ variância da amostra 2 ;

$n_{1}=$ número de observações da amostra 1 ;

$n_{2}=$ número de observações da amostra 2 .

Na consulta à tabela de $t$ de Student, os graus de liberdade (ט) devem ser arredondados para o inteiro mais próximo.

A altura de todas as plantas de E. dunnii foram medidas logo após o plantio. A medição foi repetida aos 6, 14 e 17 meses de idade, após o primeiro período vegetativo, após o primeiro inverno e após o segundo período vegetativo, respectivamente.

A cobertura foi retirada após o primeiro inverno, quando as plantas de E. dunnii apresentavam doze meses de idade e altura superior a dois metros. Essa remoção da cobertura foi realizada de forma criteriosa, direcionando as copas das árvores de P. taeda para os ramais de colheita. Para isso utilizaramse cunhas e técnicas de corte direcional.

Após a colheita de todas as árvores da cobertura, contou-se o número de plantas de $E$. dunnii afetadas. Num primeiro momento procurou-se separar as plantas danificadas com a derrubada e pelo arraste das árvores. Como o número de árvores danificadas foi muito baixo, as causas de dano foram agrupadas.

$\mathrm{Na}$ medição realizada aos quatorze meses, já sem a cobertura de pinus, foram incluídas as variáveis DAP e diâmetro do colo, medidos com fita diamétrica e suta, respectivamente.

\section{RESULTADOS E DISCUSSÃO}

\section{Temperaturas sob as diferentes coberturas}

Constatou-se que a presença de cobertura torna as temperaturas mínimas mais quentes e as máximas mais frias. Resultados semelhantes foram relatados por Angestam et al. (2003), que observaram a tendência de temperaturas mais baixas e maior ocorrência de geadas em locais desprovidos de árvores. Horiuchi; Sakai (1978) também observaram temperaturas mínimas moderadas durante a noite e diminuição da temperatura durante o dia em um plantio de Cryptomeria japonica sob a cobertura de um povoamento de pinus com 18 anos no Japão.

Para Camargo et al. (1993), temperaturas abaixo de $3{ }^{\circ} \mathrm{C}$, medidas nos abrigos, ocasionam danos às plantas. Estudos relatam que a diferença entre a temperatura medida no abrigo termométrico $(1,5 \mathrm{~m}) \mathrm{e}$ a medida na relva varia de $3,3{ }^{\circ} \mathrm{C}$ (SILVA; SENTELHAS, 2001) a $7{ }^{\circ} \mathrm{C}$ (GRODZKI et al., 1996).

Segundo Grodzki et al. (1996), as maiores diferenças são encontradas nas noites de perfeita estabilidade atmosférica.

Verificou-se que muitas noites com temperaturas mínimas inferiores a $-1{ }^{\circ} \mathrm{C}$ foram seguidas por dias com temperaturas máximas elevadas. Alguns autores citam essa tendência, relatando que noites com temperaturas muito baixas, com ocorrência de geadas, frequentemente são seguidas por dias ensolarados, com temperaturas muito altas (QUERALTO, 1971; MASSIGNAM; DITTRICH, 1998). Segundo os mesmos autores, esse fato está associado com noites de céu limpo, nas quais a perda de calor da superfície terrestre é maior.

A variação de $20{ }^{\circ} \mathrm{C}$ em um período de 12 horas é relatado como um caso extremo por FAO (1979). Variações dessa magnitude foram observadas em 13 dias para o TCA e 9 para os tratamentos T20 e T50. Esse fato foi responsável, provavelmente, por parte dos danos observados. 
A figura 2 mostra as temperaturas máximas médias e mínimas médias e suas amplitudes de variação.

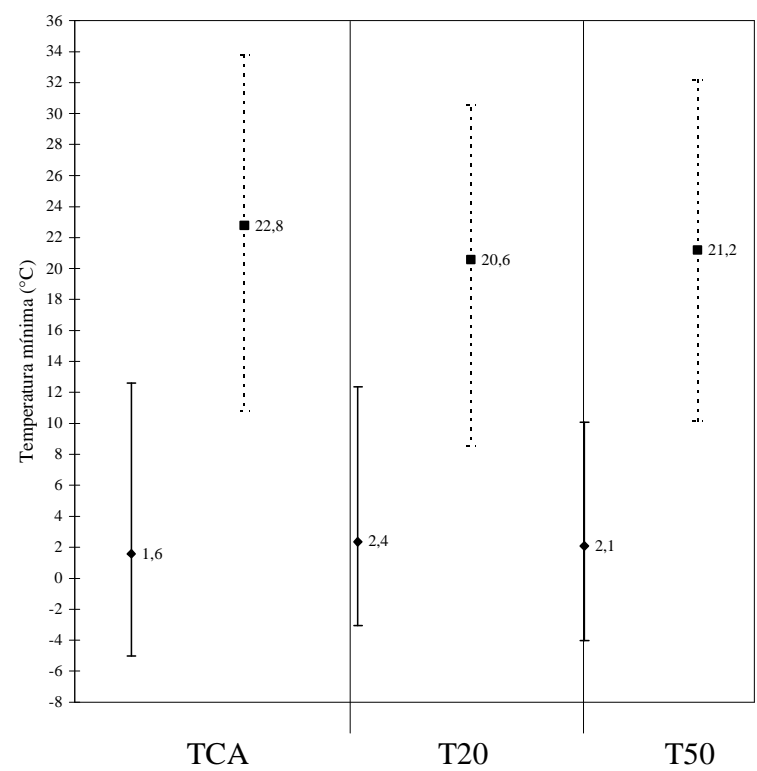

Figura 2. Temperaturas mínimas médias (linha cheia) e máximas médias (linhas pontilhadas) observadas nos tratamentos TCA, T20 e T50, e suas respectivas amplitudes de variação.

Figure 2. Average minimum (solid lines) and average maximum (dashed lines) temperatures observed on the treatments TCA, T20 and T50, and its respective variation range.

Ao analisar os extremos superiores e inferiores das temperaturas máximas médias e mínimas médias na figura 2, verifica-se que a presença de árvores diminui a amplitude de variação térmica. Larcher (1975) também cita a maior estabilidade térmica sob cobertura.

$\mathrm{O}$ tratamento T20 foi mais eficiente que o T50 no que se refere à diminuição da amplitude de variação térmica, elevando a temperatura mínima e reduzindo a máxima. Esse fato se deve, provavelmente, à diferença da situação na paisagem. $\mathrm{O}$ tratamento com menos árvores estava alguns metros acima na encosta, ambos em face sul.

No momento da medição das temperaturas, a altura de $1,5 \mathrm{~m}$ do abrigo termométrico correspondia à altura das plantas de E. dunnii. Os meristemas apicais estavam, portanto, expostos às temperaturas mostradas na figura 2.

Considerando as diferenças entre a temperatura da relva e do abrigo termométrico citadas na literatura, a temperatura mínima absoluta durante o experimento pode ter atingido temperaturas bem inferiores às observadas na figura 2 .

O fato de a temperatura mínima absoluta dos tratamentos T20 e T50 ser, respectivamente, 2 e 1 ${ }^{\circ} \mathrm{C}$ superior à medida no tratamento TCA pode resultar em maior proteção, mesmo que aparentemente pequena.

A proteção à perda de calor por radiação da superfície da Terra, em função da presença de cobertura arbórea, observada na figura 2, é relatada por vários autores já mencionados neste trabalho. Essa constatação teve efeitos nos resultados demonstrados a seguir.

\section{Proteção contra geadas}

Verificou-se anteriormente que a amplitude de variação da temperatura foi de fato menor em condições sob cobertura. Apesar de todas as plantas apresentarem danos, observou-se maior intensidade de danos na testemunha, a céu aberto (TCA).

As classes de danos " 2 " e " 3 " não se apresentaram cumulativas com as classes anteriores. O definhamento do meristema apical (classe 3) ocorreu independentemente da mudança de coloração das 
folhas (classe 2). Já plantas com classe de dano "4" apresentaram, além da morte da gema apical, mudança de coloração das folhas e meristemas laterais afetados.

Foram realizadas duas avaliações, nas quais os danos observados foram resultantes, principalmente, de dois períodos de geadas intensas, ocorridos nos dias 21,22 e 23 de agosto, quando a temperatura mínima observada, medida no abrigo termométrico, foi de $-4{ }^{\circ} \mathrm{C}$, e nos dias 04,05 e 06 de setembro, com temperatura mínima de $-5{ }^{\circ} \mathrm{C}$.

Segundo Paludzyszyn Filho; Santos (2005), temperaturas próximas ou abaixo de $0{ }^{\circ} \mathrm{C}$, medidas em abrigo termométrico, ocasionam danos em eucaliptos que vão desde a perda de área foliar até a morte das plantas.

Observou-se que $70 \%$ do total das plantas sofreram danos intensos (classe de dano igual ou superior a "4"), comprometendo o meristema apical. Segundo Sakai; Larcher (1987), Ferreira (1989), Koslowski et al. (1991), Balmelli (1993) e Higa et al. (1997), os danos ao meristema apical são problemáticos, por bifurcar ou ramificar o eixo principal de crescimento da árvore.

Foi observado, porém, que muitas plantas enquadradas em classe de dano igual ou superior a "4", principalmente as com maior vigor, apresentaram retomada de crescimento em um único eixo principal, o que demonstra a capacidade de recuperação das árvores após sua exposição às geadas, conforme já relatado por Higa (1998).

Constatou-se que $8 \%$ das plantas foram enquadradas na classe "6" e 91\% destas morreram. Todas as plantas enquadradas na classe " 5 " (19\%) apresentaram rachaduras no tronco e $40 \%$ destas morreram, confirmando a conclusão obtida por Higa (1997) de que a geada é fator limitante ao cultivo de E. dunnii.

Embora Sakai; Larcher (1987), Ferreira (1989) e Koslowski et al. (1991), relatem que rachaduras no caule permitem a entrada de patógenos, esse fato não foi observado no presente trabalho. Ainda com relação às rachaduras no caule, de acordo com Ferraz; Coutinho (1984), plantas com esse tipo de dano apresentam lenho apodrecido ou, segundo Higa (1998), madeira morta inclusa, o que inviabiliza sua utilização como madeira sólida, pelo menos em parte do seu tronco.

Verifica-se, na figura 3, a variação diária das temperaturas máxima e mínima durante o período do experimento, na estação meteorológica mais próxima, localizada na cidade de Lages, SC $(50 \mathrm{~km}$ em linha reta).

Apesar de se observar ocorrência de geadas a partir de maio, o período no qual se constatou a ocorrência de geadas mais severas foi no final do mês de agosto e início de setembro. As geadas ocorridas nesse período, portanto, foram classificadas como tardias.

Segundo Larcher (1975) e FAO (1979), a ocorrência de geadas iniciais ou tardias, no outono ou primavera, são mais prejudiciais, por atingirem plantas pouco rustificadas. Bowers (1994) reforça essa afirmação, relatando que, na primavera, a planta volta a crescer normalmente e fica mais vulnerável aos efeitos das geadas.

A amplitude da variação térmica (Figura 3) foi claramente muito grande, principalmente no período mais frio, em que as temperaturas mais altas foram semelhantes às observadas no verão. Essa grande variação da temperatura pode ter intensificado os danos às plantas de $E$. dunnii, pois, segundo Paton (1982), a perda de resistência ao frio para algumas espécies do gênero Eucalyptus ocorre com a exposição da planta a apenas 2-3 dias mais quentes.

Foram observadas 12 geadas durante os meses de maio a novembro, no local do experimento. Ao relacionar os dias de ocorrência de geada com a figura 3, verifica-se que uma temperatura abaixo de $4,5{ }^{\circ} \mathrm{C}$ na estação meteorológica de Lages foi suficiente para se observar uma geada na área experimental. No entanto, isso não significa que em todos os dias com temperatura abaixo de $4,5{ }^{\circ} \mathrm{C}$ foram observadas geadas. Isso porque, de acordo com Massignam; Ditrich (1998), outros fatores físicos do meio, tais como o grau de nebulosidade e a velocidade do vento, podem influenciar na ocorrência desse fenômeno. Devese ressaltar ainda que a área experimental estava a $50 \mathrm{~km}$ de distância da estação meteorológica de Lages.

A frequência relativa de plantas por classe de dano e por tratamento pode ser observada na figura 4.

Observa-se nessa figura que nenhum tratamento apresentou plantas sem dano (Classe 1). Da mesma forma, Higa et al. (2000) não encontraram plantas de E. dunnii sem dano, após uma geada em Campo do Tenente. 


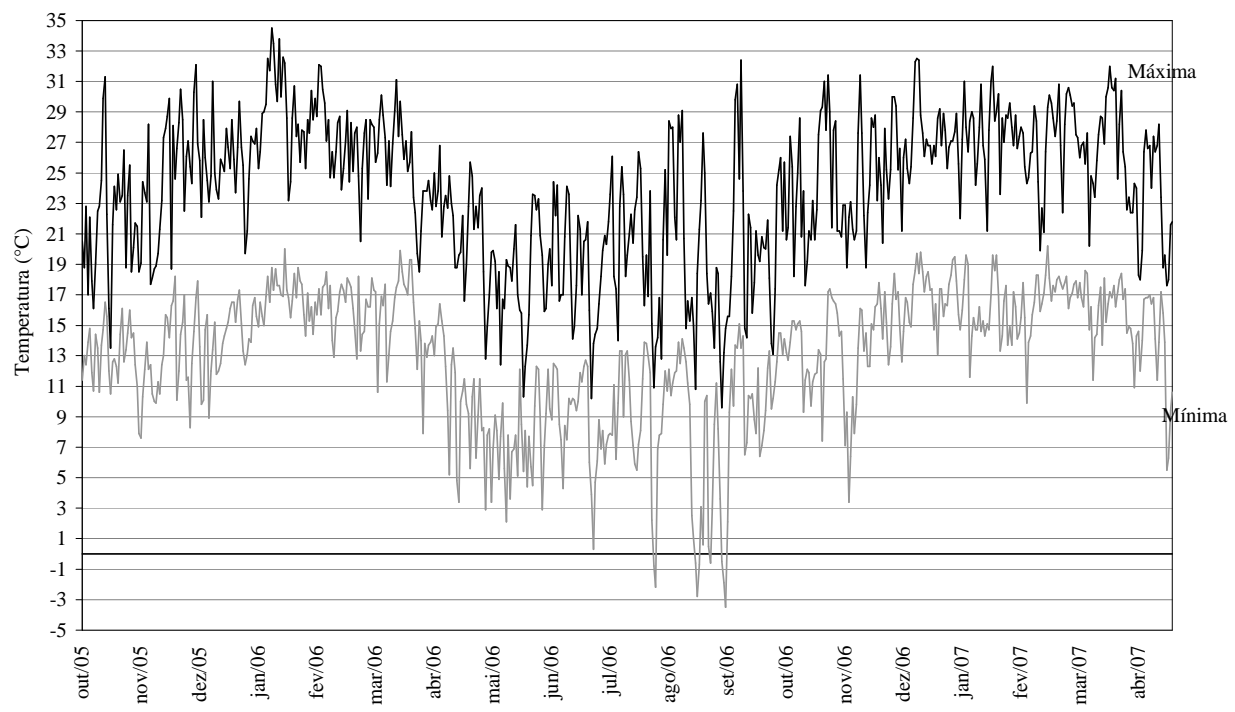

Fonte: EPAGRI/CIRAM. Estação Meteorológica de Lages, SC.

Figura 3. Flutuação das temperaturas máxima e mínima durante o experimento.

Figure 3. Maximum and minimum temperature fluctuation during the experiment period.

Tomando como referência a linha da frequência média para todos os tratamentos, verifica-se maior intensidade dos danos no tratamento TCA. À medida que se aumenta a intensidade de cobertura, diminui-se a intensidade dos danos observados.

A variação da intensidade de dano dentro de um mesmo tratamento pode ser explicada pela variabilidade genética de resistência às geadas em nível individual (HIGA, 1998).

TCA

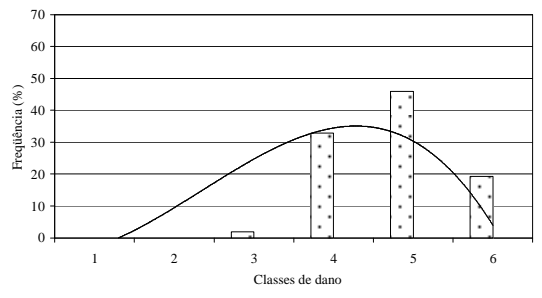

T20

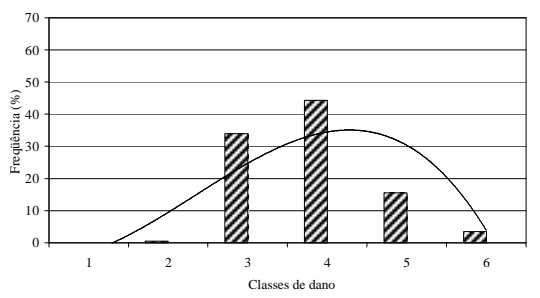

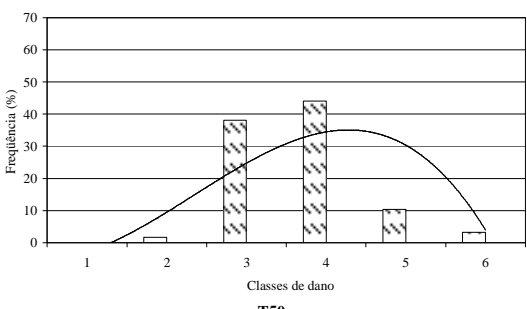

T50

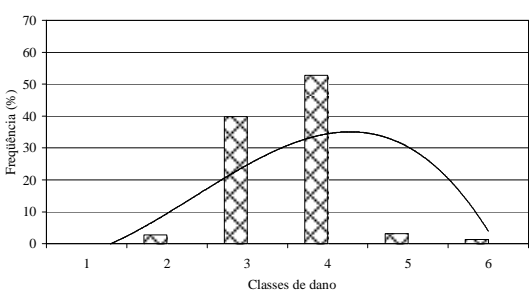

Figura 4. Frequências relativas de plantas por classe de dano e por tratamento e linha da frequência média para todos os tratamentos.

Figure 4. Relative frequency of plants per damage class and treatment and average frequency line for all treatments.

A figura 5 mostra a intensidade de dano médio para as quatro situações estudadas. Quanto maior o valor da média da classe de dano, mais intensos foram os danos. 
Com base na figura 5, conclui-se que a cobertura de pinus sobre as plantas de E. dunnii acarretou benefícios para elas no que se refere à proteção contra geadas. $\mathrm{O}$ tratamento $\mathrm{T} 50$ foi o que mais protegeu as plantas. Os tratamentos TB e T20 não se diferenciaram entre si, foram inferiores ao T50 e superiores ao TCA, a um nível de $95 \%$ de probabilidade.

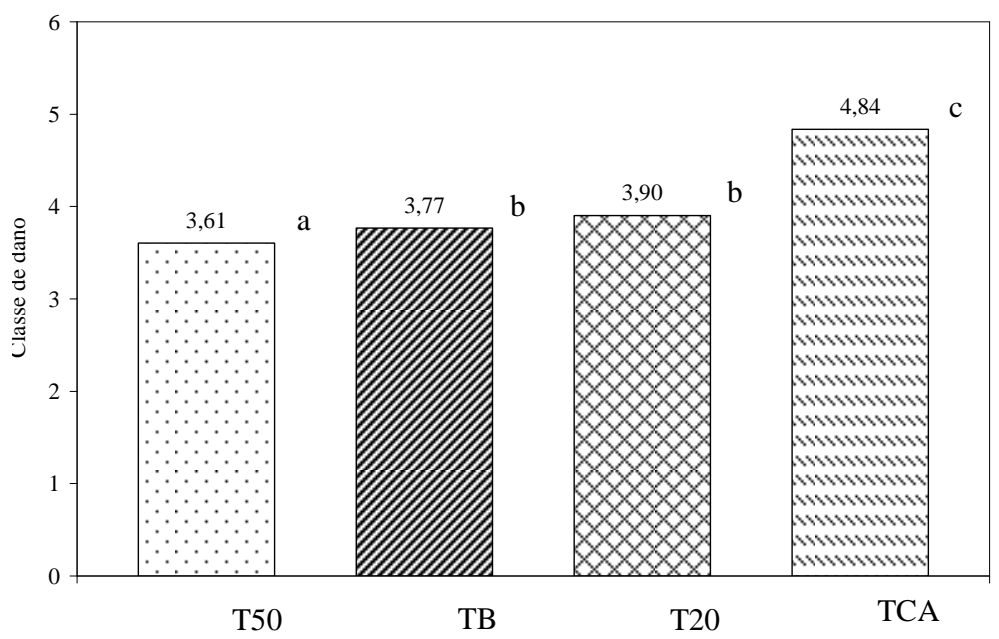

Médias seguidas da mesma letra não diferem estatisticamente entre si, segundo o teste Fischer-Behrens, com 95\% de probabilidade. Figura 5. Danos decorrentes de geadas. Valores médios por tratamento.

Figure 5. Frost damages. Average values per treatment.

Diversos autores relatam uma diferença no microclima em áreas com e sem árvores (LARCHER, 1975; BURSCHEL; HUSS, 1997; CARAMORI et al., 1999; LANGVALL; LÖFVENIUS, 2002), relacionando vários aspectos físicos que acarretam tal diferenciação. Para este trabalho, o fundamental é a menor perda de calor do solo e da superfície dos corpos sob cobertura para a atmosfera pelo processo de radiação. Ao diminuir a perda de calor, portanto, o tratamento com maior número de árvores por hectare (T50) conseguiu proteger mais eficientemente as plantas de E. dunnii.

Em climas mais severos, como o temperado, a manutenção de cobertura com o objetivo de proteger as plantas jovens é amplamente utilizado. Por exemplo, Angestam et al. (2003), estudando a regeneração natural de Fagus sylvatica na Suécia, também observaram maior mortalidade em plantios a céu aberto, comparado com outros sob cobertura.

A intensidade média de dano decorrente de geadas, sua amplitude e coeficiente de variação em torno da média são apresentados na tabela 3 .

Tabela 3. Dano médio, amplitude de dano e coeficiente de variação em porcentagem para os diferentes tratamentos.

Table 3. Average damage, damage range and coefficient of variation (\%) for the different treatments.

\begin{tabular}{lccc}
\hline Tratamento & Dano médio & Amplitude de dano & CV\% \\
\hline T50 & $3,61 \mathrm{a}$ & $2-6$ & 18,5 \\
TB & $3,77 \mathrm{~b}$ & $2-6$ & 21,6 \\
T20 & $3,90 \mathrm{~b}$ & $2-6$ & 21,6 \\
TCA & $4,84 \mathrm{c}$ & $3-6$ & 15,4 \\
\hline
\end{tabular}

Médias seguidas da mesma letra não diferem estatisticamente entre si, segundo o teste FischerBehrens, com $95 \%$ de probabilidade.

Observa-se, na tabela 3, que os coeficientes de variação em porcentagem para os dois tratamentos extremos (T50 e TCA) foram menores. Isso significa que a dispersão dos valores em torno da média foi pequena, comprovando a eficiência na proteção para o T50 e a ausência de proteção no TCA.

Os tratamentos com cobertura podem ter contribuído na proteção contra os danos ao sombrear o colo de algumas plantas de E. dunnii. Segundo Horiuchi; Sakai (1978), a resistência ao frio pode ter 
relação com o sombreamento do colo da planta. Em estudo realizado pelos mesmos autores, o sombreamento do colo de plantas de Cryptomeria japonica (L. F.) D. Don foi responsável por manter a resistência já adquirida às geadas.

Observou-se a tendência das plantas menores serem mais afetadas pela geada em todos os tratamentos, reafirmando as conclusões obtidas por FAO (1979), Paton (1982), Ferraz; Coutinho (1984), Balmelli (1993) e Higa et al. (1997). Essa constatação era esperada, visto que a temperatura nas camadas mais próximas ao solo é menor (GRODZKI et al., 1996; SILVA; SENTELHAS, 2001).

Conclui-se que o sistema de plantio sob cobertura não soluciona definitivamente todos os problemas causados pelas geadas. Esse sistema pode não ser suficiente para evitar que as plantas sejam fortemente danificadas pelo frio ou mesmo sejam mortas, caso ocorram variações térmicas abruptas ou com temperaturas mais baixas que as do período estudado, mas trata-se de uma forma de diminuir os danos causados por geadas em plantas de E. dunnii em regiões com invernos severos.

\section{Resiliência}

Verifica-se, na figura 6, que as plantas com maiores alturas antes das geadas (abril/2006) foram menos afetadas por elas.

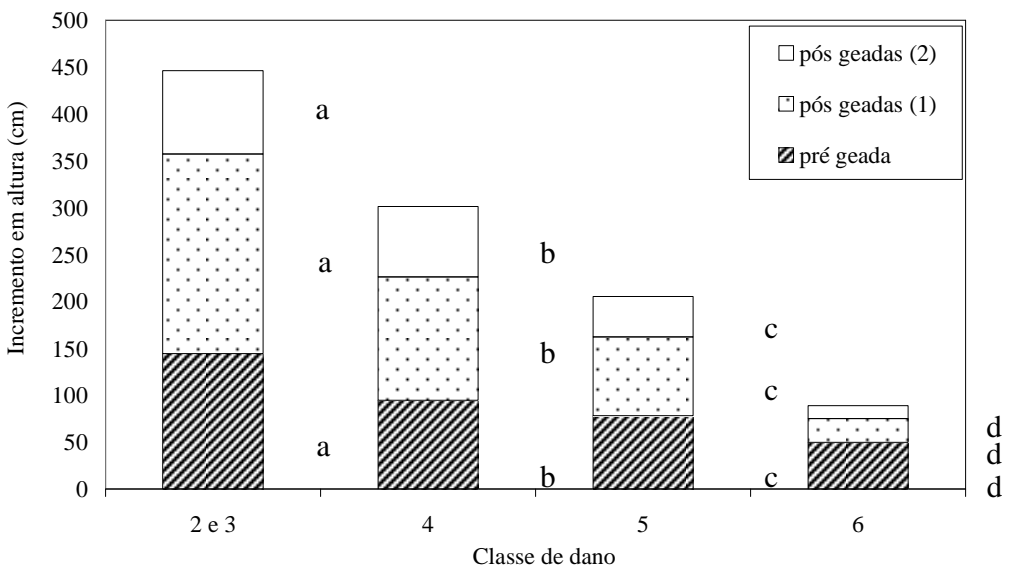

Médias seguidas da mesma letra não diferem estatisticamente entre si, segundo o teste Fischer-Behrens, com 95\% de probabilidade.

Figura 6. Alturas médias das plantas de Eucalyptus dunnii em três diferentes momentos: pré-geada (abril/2006), pós-geada (1) (janeiro/2007) e pós-geada (2) (abril/2007).

Figure 6. Avarage height of Eucalyptus dunnii plants at three differents ages: before the frost (April/2006), after frost (1) (January/2007) and after frost (2) (April/2007).

Observa-se também que, quanto mais intensa a classe de dano na qual a planta foi enquadrada, menor foi seu incremento em altura após a ocorrência de geadas, tanto para o primeiro período (janeiro/2007) como para o segundo (abril/2007). A comparação das médias foi realizada entre as diferentes classes de dano.

De forma semelhante, Ferraz; Coutinho (1984) concluíram que árvores dominadas de E. saligna com nove anos de idade, no município de Salto de Pirapora, SP, sofreram maiores danos causados por geadas $\left(-1^{\circ} \mathrm{C}\right)$ em relação às codominantes $\mathrm{e}$, principalmente, às dominantes.

Diferenças significativas no crescimento após danos ocasionados por geadas também foram encontrados por Higa et al. (2000), testando diferentes progênies de E. dunnii em Campo do Tenente, PR. Os mesmos autores verificaram, porém, de forma contrária ao apresentado na figura 6, que plantas com maior crescimento antes da geada foram menos resilientes, apresentando menor taxa de crescimento depois da geada.

A presença da cobertura no atual trabalho pode ter relação com as conclusões distintas observadas no parágrafo anterior. $\mathrm{O}$ fato de as plantas mais altas estarem sob uma cobertura que as protegeu das geadas difere do trabalho de Higa et al. (2000), no qual as plantas mais altas estavam desprovidas de proteção. 
Observou-se que muitas plantas que haviam sido fortemente afetadas pela geada apresentaram brotação vigorosa a partir da base da planta. Verificou-se, ainda, relação entre a classe de dano, o tratamento no qual a planta se encontrava e o tamanho da rebrota. Para avaliar tal relação, as plantas foram separadas por tratamento, considerando somente as plantas enquadradas na classe de dano 6 (morte da parte aérea). Os resultados são apresentados na tabela 4.

Tabela 4. Porcentagem de plantas com morte da parte aérea e altura da rebrota para os diferentes tratamentos.

Table 4. Percentage of plants with above ground death and regrowth height for the different treatments.

\begin{tabular}{lcc}
\hline Tratamento & $\begin{array}{c}\text { Plantas com morte da parte aérea } \\
(\%)\end{array}$ & $\begin{array}{c}\text { Altura da rebrota } \\
(\mathrm{cm})\end{array}$ \\
\hline TCA & $55,8 \mathrm{a}$ & $77,9 \mathrm{a}$ \\
TB & $9,7 \mathrm{~b}$ & $144,3 \mathrm{~b}$ \\
T20 & $9,8 \mathrm{~b}$ & $-148,6 \mathrm{~b}$ \\
T50 & $2,3 \mathrm{c}$ & $150,0 \mathrm{~b}$ \\
\hline
\end{tabular}
probabilidade.

Médias seguidas da mesma letra não diferem estatisticamente entre si, segundo o teste Fischer-Behrens, com $99 \%$ de

A porcentagem de plantas com morte da parte aérea foi estatisticamente maior no tratamento TCA e menor no tratamento T50 (Tabela 4). Além disso, a altura da rebrota foi maior na presença da cobertura, independentemente do tipo e da intensidade dessa cobertura.

Verificou-se que o solo da área de campo, apesar de quimicamente mais fértil, apresentava maior densidade que o solo dos tratamentos sob cobertura. Dessa forma, a altura da rebrota pode ter sido influenciada pelas condições físicas do solo.

\section{Crescimento do Eucalyptus dunnii}

Constatou-se que, dentre os tratamentos com cobertura, o aumento de árvores de $P$. taeda afetou negativamente o crescimento em altura das plantas de E. dunnii (Figura 7).

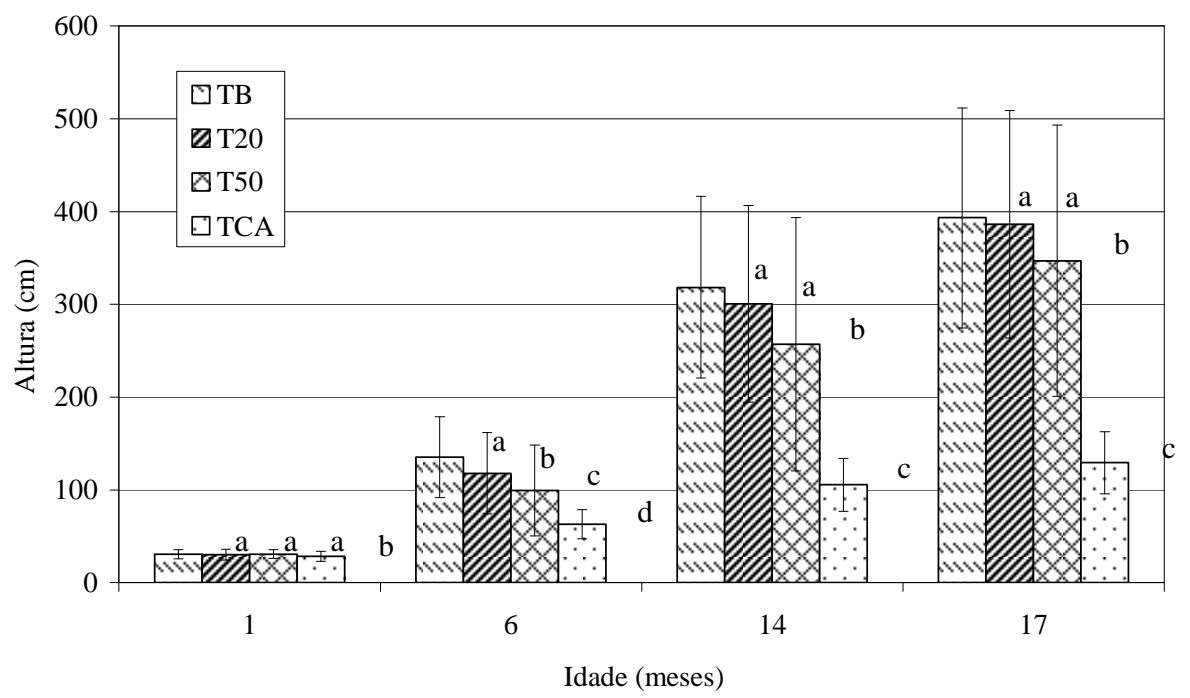

Médias seguidas da mesma letra em cada idade não diferem estatisticamente entre si, segundo o teste Fischer-Behrens, com 99\% de probabilidade.

Figura 7. Crescimento médio em altura para o Eucalyptus dunnii e suas respectivas amplitudes de variação, nos diferentes tratamentos, em quatro diferentes idades.

Figure 7. Eucalyptus dunnii average height growth and its respectives variation ranges on different treatments at four different ages.

A testemunha (TCA) foi o tratamento que apresentou o menor crescimento em todas as idades avaliadas. Além dos intensos danos decorrentes das geadas, esse fato pode estar relacionado também com 
as propriedades físicas do solo. Conforme já relatado, a maior compactação do solo na testemunha (TCA) pode ter influenciado negativamente o crescimento das plantas.

Em estudo realizado em casa de vegetação por Silva et al. (2002), a compactação do solo foi responsável pela redução do crescimento das raízes de Eucalyptus camaldulensis Dehn. Muito embora o trabalho citado tenha sido realizado com Latossolo, condição diferente do atual experimento, as consequências para as plantas podem ser relacionadas.

A partir do décimo quarto mês, as alturas médias dos tratamentos TB e T20 passaram a ser estatisticamente semelhantes e superiores às demais.

Dentre os tratamentos sob cobertura, pode-se afirmar que todas as diferenças observadas no crescimento são oriundas exclusivamente dos tratamentos aplicados. A classificação das áreas em termos de qualidade de sítio comprovou a semelhança entre elas, com $95 \%$ de probabilidade.

Analisando as amplitudes de variação, observa-se que há uma grande variabilidade no crescimento em altura entre as plantas dentro de um mesmo tratamento.

Verificou-se, portanto, que a cobertura proporcionou maior proteção contra geadas, ao mesmo tempo em que influenciou negativamente o crescimento das plantas de E. dunnii.

A influência negativa da cobertura sobre o crescimento em diâmetro das plantas de E. dunnii, pode ser observada na tabela 5 .

Tabela 5. Diâmetro de colo (Øcolo) e diâmetro à altura do peito (DAP) das plantas de Eucalyptus dunnii nas diferentes intensidades de cobertura.

Table 5. Collar diameter (Øcollar) and diameter at breast high (DBH) of Eucalyptus dunnii plants.

\begin{tabular}{lcc}
\hline Tratamento & $\begin{array}{c}\boldsymbol{\emptyset}_{\text {colo }} \\
(\mathbf{m m})\end{array}$ & $\begin{array}{c}\text { DAP } \\
(\mathbf{m m})\end{array}$ \\
\hline TB & $64,5 \mathrm{a}$ & $35,2 \mathrm{a}$ \\
T20 & $64,6 \mathrm{a}$ & $35,5 \mathrm{a}$ \\
T50 & $54,4 \mathrm{~b}$ & $30,7 \mathrm{a}$ \\
TCA & $21,2 \mathrm{c}$ & - \\
\hline
\end{tabular}

Médias seguidas da mesma letra não diferem estatisticamente entre si, segundo o teste FischerBehrens, com $99 \%$ de probabilidade.

Observa-se, na tabela 5, a influência negativa da intensidade de cobertura no crescimento em diâmetro de colo das plantas de E. dunnii no T50. Para a variável DAP não foram encontradas diferenças estatísticas entre os tratamentos. A grande diferença no diâmetro de colo e a ausência de DAP, por falta de altura das plantas no tratamento TCA, devem-se ao crescimento inferior, decorrente do efeito negativo da geada e possivelmente da compactação do solo.

Os diâmetros de colo dos tratamentos TB e T20 foram semelhantes e superiores estatisticamente aos demais. Existe, portanto, um limite de intensidade de cobertura acima do qual há perda significativa de crescimento em altura e diâmetro de colo. Essas informações reforçam a ideia de Angestam et al. (2003), que afirmam que a intensidade ideal de cobertura deve ser uma combinação de proteção contra o frio excessivo e o mínimo efeito negativo no crescimento.

Do ponto de vista prático, o tratamento TB é muito interessante, em função de proporcionar a segunda melhor proteção contra geadas e o melhor crescimento das plantas. Após a retirada das árvores de $P$. taeda, porém, permanece uma faixa sem uso, que não foi plantada com $E$. dunnii. Sugere-se, para mitigar essa desvantagem, efetuar o plantio do E. dunnii em blocos, formando um mosaico, ou deixar a bordadura até o corte final do eucalipto, que pode ser realizado aos 15 anos de idade.

A amplitude de variação do crescimento em altura observada na figura 7 pode ser vista como uma vantagem, pois diminui a competição entre as plantas e posterga um possível desbaste.

Além disso, sabe-se que um número pequeno de árvores por hectare é suficiente para garantir o completo uso do espaço produtivo em idades avançadas. Nutto (2006) relata que se deve deixar somente 100 árvores por hectare para o corte final, quando o objetivo é obter árvores com DAP de $60 \mathrm{~cm}$, para $E$. grandis. Número este bastante inferior às atuais 1600 árvores por hectare e que permitiria, por exemplo, 3 desbastes seletivos com intensidades de $50 \%$ cada. 
Verificou-se, ainda, maior influência negativa no crescimento em altura do $E$. dunnii nas proximidades das árvores da cobertura em todos os tratamentos sob cobertura aos seis meses de idade (abril/2006).

Observou-se que a influência negativa do $P$. taeda sobre o crescimento em altura do $E$. dunnii foi mais pronunciada num raio de, aproximadamente, quatro metros. Nessa distância, portanto, será muito difícil encontrar plantas de $E$. dunnii com capacidade de se tornarem árvores dominantes.

Essa mesma tendência de maior crescimento com o aumento da distância da árvore da cobertura foi relatada por Strand et al. (2006) para coníferas crescendo sob a cobertura de Pinus sylvestris na Suécia. Segundo esses autores, essa influência negativa está relacionada com a competição por água e nutrientes entre as plantas jovens e as árvores da cobertura. figura 8 .

A precipitação e a temperatura média durante o período do experimento são apresentadas na

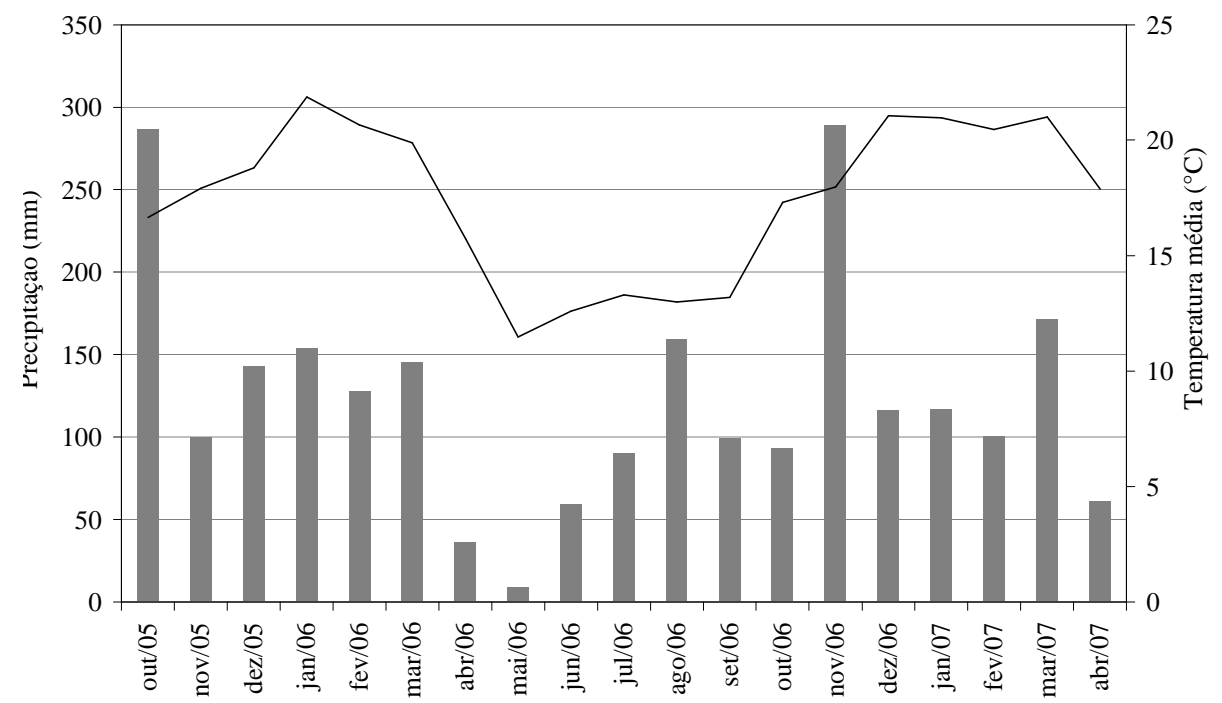

Fonte: EPAGRI/CIRAM. Estação Meteorológica de Lages, SC.

Figura 8. Precipitação (colunas) e temperatura média (linha) durante o período do experimento, outubro/2005 a abril/2007.

Figure 8. Rainfall (column) and avarage temperature (line) during the experiment period, October/2005 to April/2007.

Verifica-se na figura 8 que a precipitação para o ano de 2006 foi de $1.376 \mathrm{~mm}$, indicando um ano relativamente seco, já que, de acordo com EMBRAPA (1988), a amplitude de variação histórica da precipitação anual naquele local varia de 1.300 a $2.400 \mathrm{~mm}$. Esse fato pode ter intensificado o efeito negativo no crescimento das plantas próximas às árvores da cobertura.

\section{Remoção da cobertura: danos}

A retirada da cobertura de Pinus taeda foi realizada em dezembro de 2006, quando as plantas de E. dunnii estavam com 13 meses de idade.

Verificou-se que o porcentual de plantas de $E$. dunnii danificadas em função da remoção da cobertura foi de $1,2 \%, 2,6 \%$ e 1,5\%, para os tratamentos TB, T20 e T50, respectivamente.

O percentual de plantas de E. dunnii danificadas durante o processo de remoção da cobertura foi, portanto, pequeno. Isso se deve ao emprego de técnicas de corte direcional, derrubando as copas das árvores nas estradas e ramais de extração. Esses ramais de extração, alocados na $12^{\mathrm{a}}$ linha do plantio do povoamento de $P$. taeda, foram mantidos e utilizados para o enleiramento dos resíduos da colheita de $P$. taeda que antecedeu o plantio do E. dunnii. Por este motivo, havia grande disponibilidade de ramais para direcionar as copas das árvores da cobertura no momento de sua derrubada.

Observou-se ainda uma grande flexibilidade das plantas de E. dunnii com 13 meses de idade, o que pode ter contribuído para o pequeno percentual de dano. 
O fato de se observar maior intensidade de dano no tratamento com T20 deve-se à queda de uma copa de maiores proporções sobre um grupo de plantas ou danos com o arraste das árvores.

\section{CONCLUSÕES}

- $\mathrm{O}$ aumento da intensidade de cobertura, até 50 árvores de $P$. taeda por hectare, diminui os danos causados por geadas com temperaturas de até $-5{ }^{\circ} \mathrm{C}$ e aumenta a resiliência das plantas afetadas. Plantas menores de E. dunnii tendem a ser mais danificadas por geadas, independentemente da intensidade de cobertura sobre elas.

- Quanto maior a intensidade de cobertura, até 50 árvores de $P$. taeda por hectare, menor é o crescimento em altura e diâmetro do colo do E. dunnii, antes e após as geadas. Essa influência negativa no crescimento é maior num raio de até quatro metros em torno das árvores da cobertura de P. taeda.

- Para as condições estudadas, a intensidade de cobertura ótima foi obtida com a manutenção de uma "cortina" de árvores de $P$. taeda no perímetro do talhão (TB), distantes 66 metros entre si, que proporciona a segunda melhor proteção contra geadas e o melhor crescimento em altura e diâmetro do colo.

- O uso de técnicas de corte direcional na remoção das árvores da cobertura de $P$. taeda danifica um número insignificante de plantas jovens de $E$. dunnii.

Recomenda-se esse sistema de plantio sob cobertura para a produção de madeira de maiores dimensões, com horizontes de produção mais longos que os atuais empregados para esse gênero. Dessa forma, o efeito negativo no crescimento inicial do E. dunnii, como consequência da presença de cobertura sobre ele, pode ser tolerado, visto que os riscos de danos severos são significativamente reduzidos.

\section{AGRADECIMENTOS}

À empresa Florestal Gateados Ltda., pela concessão da área de estudo e apoio logístico durante todo o período do experimento.

\section{REFERÊNCIAS}

AGESTAM, E.; EKÖ, P. M.; NILSSON, U.; WELANDER, N. T. The effects of shelterwood density and site preparation on natural regeneration of Fagus sylvatica in Southern Sweden. Forest Ecology and Management, Amsterdam, v.176, p. 61-73, 2003.

BALMELli, G. Daño de Heladas en Eucalyptus: Evaluacion de daño en especies y origenes en el primer invierno. Tacuarembo: Instituto Nacional de Investigación Agropecuaria, 1993. (Série Técnica, n. 40).

BORGES, L. C.; FERREIRA, D. F. Comparação de duas aproximações do teste "t" com variâncias heterogêneas através de simulação. Ciência e Agrotecnologia, Lavras, v. 23, n. 2, p. 390-403, 1999.

BOWERS. M. C. Environmental Effects of Cold on Plants. In: Wilkinson, R. E. Plant-Environment Interactions. Georgia: M. Dekker, 1994. p. 391-411.

BURSCHEL, P.; HUSS, J. Grundri $\beta$ des Waldbaus. 2. Auflage. Berlin: Parey, 1997.

CAMARGO, M. B. P.; PEDRO JUNIOR, M. J.; ALFONSI, R. R. Probabilidade de ocorrência de temperaturas mínimas absolutas mensais e anuais no Estado de São Paulo. Bracatinga, Campinas, v. 52, n. 2, p. 161-168, 1993.

CARAMORI, P. H.; LEAL, A. C.; MORAIS, H. Temporary shading of young coffee plantations with pigeonpea (Cajanus cajan) for frost protection in Southern Brazil. Revista Brasileira de Agrometeorologia, Santa Maria, v. 7, n. 2, p. 195-220, 1999. 
EMBRAPA - EMPRESA BRASILEIRA DE PESQUISA AGROPECUÁRIA. Centro Nacional de Pesquisas Florestais (CNPF). Zoneamento ecológico para plantios florestais no estado de Santa Catarina. Curitiba, 1988. 113 p.

FAO. Eucalypts for Planting. 11. Food and Agriculture Organization of the United Nations. Rome, 1979.

FERRAZ, E. S. B.; COUTINHO, A. R. Efeitos da geada na madeira de Eucalyptus saligna. IPEF, Piracicaba, n. 28, p. 57-62, 1984.

FERREIRA, F. A. Patologia florestal: principais doenças florestais do Brasil. Viçosa, 1989.

GRODZKI, L.; CARAMORI, P. H.; BOOTSMA, A.; OLIVEIRA, D.; GOMES, J. Riscos de geada no estado do Paraná. Revista Brasileira de Agrometeorologia, Santa Maria, v. 4, n. 1, p. 93-99, 1996.

GUEDES, S. F. F. Carbono orgânico e atributos do solo em áreas florestais no Planalto dos Campos Gerais, SC. 47 p. Dissertação (Mestrado em Solos) - Universidade Estadual de Santa Catarina, Lages, 2005.

HIGA, R. C. V. Studies on the physiology of frost resistence in Eucalyptus viminalis LABILL. M.Sc. Thesis - Australian National University, 1989.

HIGA, R. C. V.; HIGA, A. R.; TREVISAN. R.; SOUZA, M. V. R. Comportamento de Vinte Espécies de Eucalyptus em Área de Ocorrência de Geadas na Região Sul do Brasil. In: IUFRO CONFERENCE ON SILVICULTURE AND IMPROVEMENT OF EUCALYPTS, 1997, Salvador. Proceedings... Colombo: EMBRAPA, 1997. v. 4.

HIGA, R. C. V. Avaliação e recuperação de Eucalyptus dunnii Maiden atingidos por geadas em Campo do Tenente, PR. Tese (Doutorado em Silvicultura) - Universidade Federal do Paraná, Curitiba, 1998.

HIGA, R. C. V.; HIGA, A. R.; TREVISAN, R.; de SOUZA, M. V. R. Resistência e Resiliência a geadas em Eucalyptus dunnii MAIDEN Plantados em Campo do Tenente, PR. Boletim de Pesquisa Florestal, Colombo, n. 40, p. 67-76, 2000.

HORIUCHI, T.; SAKAI, A. Effect of solar radiation on frost damage to young cryptomerias. In: Li, P.H. e Sakai, A. Plant cold hardiness and freezing stress. New York: Academic, 1978. . p. 417-426.

IWAKIRI, S.; KEINERT JR., S.; PRATA, J. G.; ROSSO, S. Produção de painel compensado estrutural de Eucalyptus grandis e Eucalyptus dunnii. Revista Floresta, Curitiba, v. 37, n. 3, p. 363-367, 2007.

KOZlowski, T. T.; KRAMER, P. J.; PALlaRdy, S. G. The Physiological Ecology of Woody Plants. San Diego: Academic, 1991.

LANGVALL, O.; LÖFVENIUS, M. O. Effect of shelterwood density on nocturnal near-ground temperature, frost injury risk and budburst date of Norway spruce. Forest Ecology and Management, Amsterdam, v. 168, p. 149-161, 2002.

LARCHER, W. Physiological Plant Ecology. Berlin: Springer-Verlag, 1975. 252 p.

MASSIGNAM, A. M.; DITTRICH, R. C. Estimativa do número médio e da probabilidade mensal de ocorrência de geadas para o estado de Santa Catarina. Revista Brasileira de Agrometeorologia, Santa Maria, v. 6, n. 2, p. 213-220, 1998.

MATTHEWS, J. D. Silvicultural Systems. Oxford: Clarendon, 1989. 284 p.

NUTTO, L.; SPATHELF, P.; SELING, I. Management of individual tree diameter growth and implications for pruning for Brazilian Eucalyptus grandis Hill ex. Maiden. Revista Floresta, Curitiba, v. 36, n. 3, p. 397-413, 2006.

PALUDZYSZYN FILHO, E.; dos SANTOS, P. E. T. Considerações sobre o plantio de Eucalyptus dunnii, no estado do Paraná. Comunicado Técnico, Colombo, 141, 2005. 
PATON, D. M. A mechanism for frost resistence in Eucalyptus. In: Li, P.; Sakai, A. Plant cold hardiness and freezing stress. Sapporo: Academic, 1982. p. 77-92.

QUERALTO, F. D. Práctica de la defensa contra heladas. Dilagro: Lerida, 1971. 384 p.

SACHS, L. Angewandte Statistik. Zugleich vierte, Berlin: Springer-Verlag, 1973. 545 p.

SAKAI, A.; LARCHER, W. Frost Survival of Plants: responses and adaptation to freezing stress. Innsbruck: Springer-Verlag, 1987.

SILVA, J. G.; SENTELHAS, P. C. Diferença entre temperatura mínima do ar medida no abrigo e na relva e probabilidade de sua ocorrência em eventos de geadas no Estado de Santa Catarina. Revista Brasileira de Agrometeorologia, Santa Maria, v. 9, n. 1, p. 9-15, 2001.

SILVA, S. R.; BARROS, N. F.; NOVAIS, R. F.; PEREIRA, P. R. G. Eficiência nutricional de potássio e crescimento de eucalipto influenciados pela compactação do solo. Revista Brasileira Ciência do Solo, Viçosa, MG, n. 26, p. 1001-1010, 2002.

SMITH, D. M. The practice of silviculture. 8. ed. New York: J. Wiley and Sons, 1986. 527 p.

STRAND, M.; LÖFVENIUS, M. O.; BERGSTEN, U.; LUNDMARK, T.; ROSVALL, O. Height growth of planted conifer seedlings in relation to solar radiation and position in scots pine shelterwood. Forest Ecology and Management, Amsterdam, v. 224, p.258-265, 2006.

WALTERS, J. R.; BELL, T. L. Growth of Eucalyptus obliqua regeneration following overstorey removal. Forest Ecology and Management, Amsterdam, v. 219, p. 185-198, 2005. 